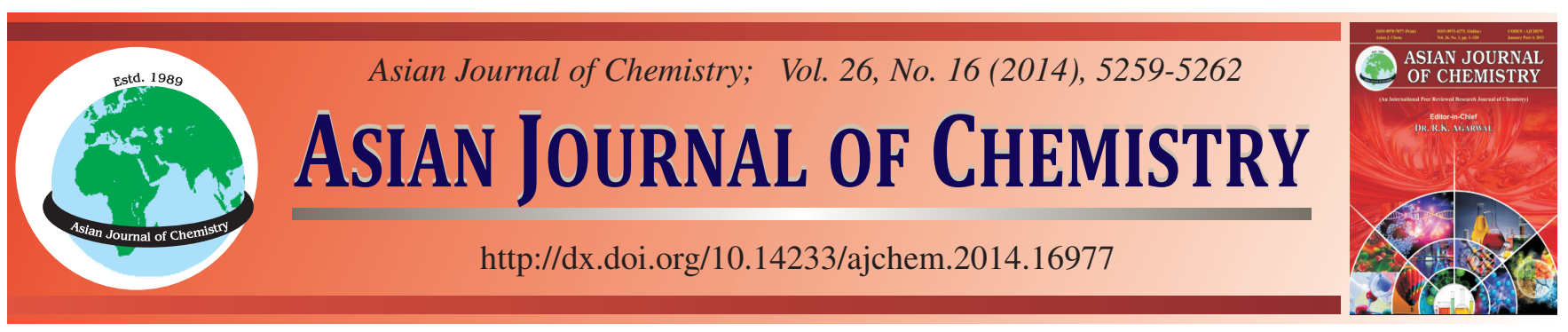

\title{
Assessment and Analysis of Different Extraction Approaches for Trace Metal Content in Suaeda glauca Bge Leaf and Seed
}

\author{
X.H. WANG ${ }^{*}$, Y.L. Gu, F.J. Wen and W. ZHU
}

\begin{abstract}
${ }^{1}$ Jiangsu Provincial Key Laboratory of Coastal Wetland Bioresources and Environmental Protection, Department of Chemistry, Yancheng Teachers University, Xiwang Road, Yancheng 224051, Jiangsu Province, P.R. China

${ }^{2}$ Institute of Applied Chemistry \& Environmental Engineering, Department of Chemistry, Yancheng Teachers University, Yancheng 224051, Jiangsu Province, P.R. China
\end{abstract}

*Corresponding author: Tel/Fax: +86 515 88233188; E-mail: wangxhong1227@163.com

\begin{abstract}
The contents of selected toxic trace metals $(\mathrm{Cu}, \mathrm{Pb}, \mathrm{Cd}$ and $\mathrm{Cr})$ and macronutrients $(\mathrm{Na}, \mathrm{Mg}$ and $\mathrm{Ca})$ in Suaeda glauca Bge, were extracted by four approaches containing conventional immersion approach, ultrasonic-assisted extraction, microwave-assisted extraction and acid digestion approach, then analyzed by flame atomic absorption spectrophotometer (FAAS). The comparison of the results showed that the metal contents released were approximately equal in former three approaches, but lower than those of acid digestion approach that extracted entire metals from Suaeda glauca Bge leaf and seed. The contents of metals from the leaf and seed of $S$. glauca were found at different levels, and showed a similar trend in the following order: $\mathrm{Na}>\mathrm{Cu}>\mathrm{Ca}>\mathrm{Mg}>\mathrm{Cd}>\mathrm{Pb}>\mathrm{Cr}$, but the values of metal in leaf showed higher than those of seed except $\mathrm{Na}$ and $\mathrm{Ca}$.. Meanwhile Suaeda glauca Bge was found to be a good hypertolerant plant for $\mathrm{Cu}$.
\end{abstract}

Keywords: Microwave-assisted extraction, Ultrasonic-assisted extraction, Suaeda glauca Bge, Trace metal.

\section{INTRODUCTION}

Metals in contaminated soils, sediments and waters may probably be due to the input of untreated waste water sewage from the industries sites and effluent from human activities, such as metal finishing, paint pigment and battery manufacturing, leather tanning, pesticides, mining activities. However, metals are non-biodegradable and can keep long-term retention in water as well as soil environment, so that they may also be transported into groundwater or be absorbed by plants. In recent days, the removal of toxic metals has gradually been a hot topic ${ }^{1}$, especially in the development of more wetland researches. There are a number of researches on the problem of the important role of plant in removal metals, which involves chemical and physical changes in the plant tissues.

Previous studies found that many wetland plants such as duckweed $^{2}$, common reed ${ }^{3,4}$, can accumulate heavy metals in their tissues greatly enriched with toxic metals. Therefore they were called metallophytes so that many researchers focused the great interest on the study related to wetland plants and considered them as potential tools for environmental phytoremediation.

Suaeda glauca Bge from a family of Suaeda could thrive in soils/sediments of the constructed wetland in Dafeng seashore (the eastern part of Jiangsu, China) that located in the vicinity of chemical factories and the living area of residents. Suaeda glauca Bge not only can be used as herbal medicine because of many pharmacological activities ${ }^{5,6}$, but also can be cooked a nice food as a vegetable ${ }^{7,8}$, additionally can be used as animal feed ${ }^{7}$. But the reports about contents of toxic trace metals and macronutrients are scanty with respect to Suaeda glauca Bge in bad conditions. Therefore it was imperative to explore the present contents of trace metals and macronutrients in Suaeda glauca Bge.

This work was to considerate Suaeda glauca Bge as the subject of study with attempts at determining the extent of metal in leaf or seed of it, which was extracted by four methods, as well as assessing edible safety in comparison with food safety standards (FSS). Meanwhile it was to preliminary analyze the ability of accumulating and tolerating $\mathrm{Pb}, \mathrm{Cu}, \mathrm{Cd}$, $\mathrm{Cr}, \mathrm{Mg}, \mathrm{Na}$ and $\mathrm{Ca}$ of Suaeda glauca Bge leaf and seed. This research could be helpful to obtain knowledge on the metal toxicity of aqueous extracts from Suaeda glauca Bge and to decide whether it could be possibly phytoremediation species in our area.

\section{EXPERIMENTAL}

Sample collection and pre-treatment: The leaf of Suaeda glauca Bge was picked in March and seed in October, 2012 in Dafeng seashore, Jiangsu, China. Samples (about 1-2 kg) were 
collected and mixed randomly. Then returned to the laboratory, the samples were cleaned and air-dried in an oven at $60{ }^{\circ} \mathrm{C}$ to a constant weight, then ground with a small domestic mill for metal concentration analysis. The prepared samples were stored in labeled polypropylene containers at room temperature.

Hydrochloric acid, nitric acid and hydrogen peroxide were used throughout this work without further purification. Standard solutions of $\mathrm{Cd}, \mathrm{Cr}, \mathrm{Cu}, \mathrm{Ca}, \mathrm{Pb}, \mathrm{Mg}$ and $\mathrm{Zn}$ containing the $1000 \mathrm{mg} \mathrm{L}^{-1}$ of the corresponding metal ions were prepared. Calibration standards of each element were obtained by appropriate dilution of the standard solutions. Milli-Q water (18.2 $\mathrm{M} \Omega \mathrm{cm}^{-1}$ ) was obtained from Milli-Q Biocel system (Millipore, USA) throughout the work. P70D2 domestic microwave oven (Galanz, China) was used for microwave extraction. Determination of metals in extracts and digestion solutions was carried out by a flame atomic absorption spectrometer (FAAS, A6601, SHIMADZU, Japan) with hollow cathode lamps, using an air-acetylene flame. Instrumental conditions in details for all elements were as follows: wavelengths 422.7, 285.2, 766.5, 283.3, 228.8, 589.0 and 540.0 $\mathrm{nm}$ for $\mathrm{Ca}, \mathrm{Mg}, \mathrm{Cu}, \mathrm{Pb}, \mathrm{Cd}, \mathrm{Na}$ and $\mathrm{Cr}$, respectively, with the lamp current $8 \mathrm{~mA}$, slit width $1.3 \mathrm{~nm}$ and gas flow-rate $2 \mathrm{~L}$ $\min ^{-1}$.

\section{General procedure}

Conventional immersion approach (CIA): The metal contents of leaf and seed extract from Suaeda glauca Bge was extracted as follows: $1.502 \mathrm{~g}$ of dry powdered leaf (or seed) was put in a beaker and add $75 \mathrm{~mL}$ of Milli-Q water and sealed with plastic wrap. After standing for $72 \mathrm{~h}$, filtration and centrifugation were operated at room temperature. $1 \mathrm{~mL}$ of supernatant was taken for measuring the metal concentration using an atomic absorption spectrometer. The metal content in the extract was calculated on basis of standard curve.

Ultrasonic-assisted extraction (UAE): Suaeda glauca Bge seed was accurately weighted (1.502 g) and placed into a flask $(75 \mathrm{~mL})$. Firstly, $30 \mathrm{~mL}$ of Milli-Q water was added into the flask placed inside the ultrasonic water bath and extracted for some time at a certain temperature. After filtration followed by the centrifuge for $0.5 \mathrm{~h}$, secondly, $25 \mathrm{~mL}$ of Milli-Q water was added into the solid residue with same operration above and thirdly $20 \mathrm{~mL}$ of Milli-Q water. Filtrate of three times was merged together for determination of the metal concentration. Based on results, optimal parameters in ultrasonic-assisted extraction were obtained.
Microwave-assisted extraction (MAE): This method was carried out using $1.502 \mathrm{~g}$ dry sample powder (leaf or seed) from Suaeda glauca Bge in a beaker, which was put into Milli$\mathrm{Q}$ water, then sealed with plastic wrap. It was followed by putting into the microwave oven for a certain time and power, respectively. After filtration and centrifuge, FAAS analysis were followed and extraction condition containing irradiation time, liquid-solid ratio and irradiation power were optimized on basis of previous experimental results.

Acid digestion approach (ADA): The total contents of heavy metals in the samples were measured by digestion with $\mathrm{H}_{2} \mathrm{O}_{2}$, which was considered as a quality control procedure. Suaeda glauca Bge leaf or seed (1.5020 g) were accurately weighed and placed in the beaker, which was added the mixture of $16 \mathrm{~mL} \mathrm{HNO}_{3}$ and $4 \mathrm{~mL} \mathrm{H}_{2} \mathrm{O}_{2}$. After standing for $24 \mathrm{~h}$, the solution was heated to evaporate almost to dryness on an electric hot plate. The sample digests were transferred into a $100 \mathrm{~mL}$ flask with $75 \mathrm{~mL}$ Milli-Q water after cooling, followed by filtration and centrifugation for $0.5 \mathrm{~h}$. One milliliter of the supernatant was taken to a $100 \mathrm{~mL}$ flask. The analysis for heavy metals was performed with an FAAS.

\section{RESULTS AND DISCUSSION}

The plant sample powder was investigated by conventional immersion approach, which is commonly explored to extract active components recorded by early document ${ }^{9}$. At present, extraction was carried out for $72 \mathrm{~h}$ without stirring at room temperature. Extraction condition was not optimized since conventional immersion approach was also considered to comparatively study the extraction efficiency of metal. The solid samples were soaked in the solvent for some components extracted on basis of the principle of similarity and compatibility. So conventional immersion approach is to separate the analyte in terms of different solubility in the solvents. Results were shown in Table-1.

We sought to obtain the smallest possible particles to achieve high leaching efficiency. The mechanism of ultrasonicassisted extraction is that the cavitation process causes the swelling of cells or the breakdown of cell-walls ${ }^{10}$, then ultrasonic waves act upon the organic molecules in the sample, breaking the metal's bond, thereby promoting the extraction of metals from the matrix ${ }^{11}$. Thus experiments parameters (time, temperature and power) in the process of ultrasonicassisted extracting the metal ions from the samples studied were selected and optimized initially in the extraction process

TABLE-1

METAL CONTENT OF Suaeda glauca Bge (SGB) LEAF OR SEED OBTAINED BY CONVENTIONAL IMMERSION APPROACH (CIA), ULTRASONIC-ASSISTED EXTRACTION (UAE), MICROWAVE-ASSISTED EXTRACTION (MAE) AND ACID DIGESTION APPROACH (ADA)

\begin{tabular}{ccc|cc|cc|cc}
\hline \multirow{2}{*}{ Metals } & \multicolumn{2}{c|}{ CIA } & \multicolumn{2}{c|}{ UAE } & \multicolumn{2}{c|}{ MAE } & \multicolumn{2}{c}{ ADA } \\
\cline { 2 - 10 } & Leaf & Seed & Leaf & Seed & Leaf & Seed & Leaf & Seed \\
\hline $\mathrm{Na}$ & $2308 \pm 34$ & $2048 \pm 31$ & $2396 \pm 27$ & $2078 \pm 25$ & $2432 \pm 24$ & $2095 \pm 25$ & $4972 \pm 34$ & $4993 \pm 34$ \\
$\mathrm{Mg}$ & $212.0 \pm 3.7$ & $213.4 \pm 3.5$ & $217.0 \pm 4.2$ & $213.9 \pm 3.5$ & $218.5 \pm 3.1$ & $214.7 \pm 3.0$ & $384.6 \pm 3.6$ & $375.6 \pm 3.7$ \\
$\mathrm{Ca}$ & $512.1 \pm 3.3$ & $528.0 \pm 3.6$ & $518.6 \pm 4.1$ & $544.4 \pm 3.9$ & $522.5 \pm 3.5$ & $546.7 \pm 3.2$ & $1213 \pm 25$ & $1223 \pm 27$ \\
$\mathrm{~Pb}$ & $3.81 \pm 0.04$ & $3.60 \pm 0.03$ & $3.94 \pm 0.05$ & $3.63 \pm 0.02$ & $3.96 \pm 0.01$ & $3.64 \pm 0.04$ & $6.65 \pm 0.06$ & $5.08 \pm 0.05$ \\
$\mathrm{Cu}$ & $743.1 \pm 3.2$ & $715.8 \pm 4.0$ & $809.9 \pm 4.6$ & $779.9 \pm 4.7$ & $812.5 \pm 3.8$ & $780.4 \pm 3.1$ & $2154 \pm 23$ & $2024 \pm 24$ \\
$\mathrm{Cd}$ & $33.82 \pm 0.13$ & $26.23 \pm 0.12$ & $36.82 \pm 0.14$ & $27.18 \pm 0.13$ & $38.27 \pm 0.12$ & $29.12 \pm 0.11$ & $84.49 \pm 0.15$ & $61.52 \pm 0.14$ \\
$\mathrm{Cr}$ & $0.81 \pm 0.01$ & $0.73 \pm 0.01$ & $1.22 \pm 0.01$ & $1.09 \pm 0.01$ & $1.22 \pm 0.01$ & $1.10 \pm 0.01$ & $1.76 \pm 0.01$ & $1.60 \pm 0.01$ \\
\hline
\end{tabular}

Results expressed as mean value \pm standard deviation $\left(\mathrm{n}=3, \mu \mathrm{g} \mathrm{g}^{-1}\right)$ 
from the samples. Three metals of $\mathrm{Ca}, \mathrm{Na}$ and $\mathrm{Cu}$ were selected for optimizating experimental conditions. Results of the experiments were shown in Fig. 1. The extraction time investigated indicated that there is a favorable value in extraction time.

The absorbance signals from FAAS remaining practically constant and the time measured in the solid-liquid system was $0.5 \mathrm{~min}$. In addition, the absorbance signal from FAAS increased up to a temperature of $60^{\circ} \mathrm{C}$, remaining constant after $60{ }^{\circ} \mathrm{C}$. This may be due to a temperature higher than $60{ }^{\circ} \mathrm{C}$ causes lower efficiency, which is gradually close to the temperature of ebullition of the solvent, thereby increasing vapor pressure and decreasing surface tension of the system, which leads to a reduction in the shock waves ${ }^{12}$. Finally, the ultrasonic instrument power has significantly impact on extraction efficiency of metal (Fig. 1).

When the instrument power approached $200 \mathrm{~W}$, the extraction efficiency of the metals in sample studied increased as the power, thereby remaining constant after $200 \mathrm{~W}$. The results indicate that the highest extraction efficiency was achieved at $200 \mathrm{~W}$. We therefore decided to use the power of $200 \mathrm{~W}$ in the next experiments, since the power may be benefit for generation of cavitation bubbles in the solution and can increase energy released ${ }^{13}$. Thereby, under optimal conditions containing $0.5 \mathrm{~h}, 60{ }^{\circ} \mathrm{C}$ and $200 \mathrm{~W}$, the experimental results were listed in Table-1.

The metal extraction obtained by microwave-assisted extraction was shown in Fig. 2. As a kind of electromagnetic wave, microwaves can be absorbed, penetrated and reflected. It may be selective absorbed by polar compounds such as water. Polar molecules can absorb microwave energy, then relax and release the energy in the form of heat ${ }^{14,15}$. With the microwave extraction technique in various fields widespread application. The extraction liquid-solid ratio, power and irradiation time are very important factors in the extraction process, therefore, they were optimized. It can be observed from Fig. 2 that the maximum content of three metals were released at $60 \mathrm{~s}$ for irradiation time, $80: 1 \mathrm{~mL} \mathrm{~g}^{-1}$ for liquid-solid ratio and $500 \mathrm{~W}$ for irradiation power in microwave-assisted extraction approach.

Total metals from Suaeda glauca Bge leaf or seed were measured by acid digestion approach and shown in Table-1. the results obtained by conventional immersion approach, ultrasonic assisted extraction and microwave-assisted extraction were comparable to those by acid digestion approach. The content of each metal in studied plant was expressed by mean content $\left(\mu \mathrm{g} \mathrm{g}^{-1}\right) \pm$ standard deviation. As can be seen, the slight differences were observed among conventional immersion approach, ultrasonic-assisted extraction and microwave-assisted extraction except acid digestion approach. The contents of seven metals released have gradually increased. In three approaches, conventional immersion approach has released lowest metals, followed by ultrasonic-assisted extraction and microwave-assisted extraction, which have almost extracted equal contents of metals. However, the overall results in microwave-assisted extraction have equal or higher extraction contents of metals than those in ultrasonic-assisted extraction. It can be inferred from this results that conventional immersion approach, ultrasonic-assisted extraction and microwave-assisted extraction only extracted free metals in plants compared with acid digestion approach. Moreover, the values

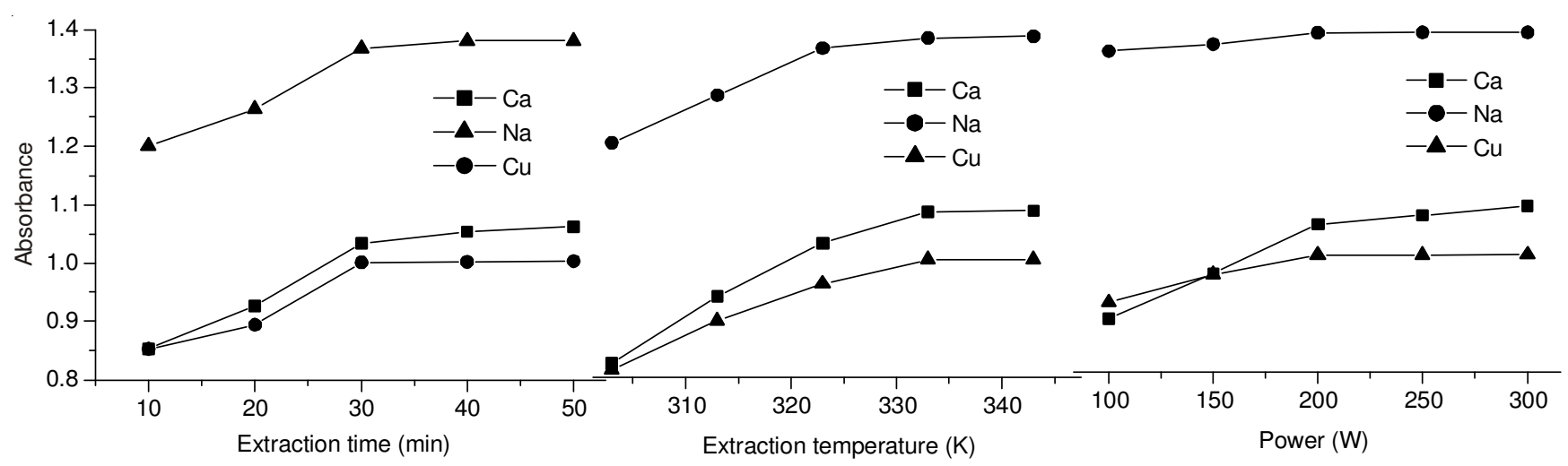

Fig. 1. Effect of extraction time, temperature and power on the ultrasonic-assisted extraction process of $\mathrm{Ca}, \mathrm{Na}$ and $\mathrm{Cu}$ extraction from Suaeda glauca Bge leaf. Solvent: water, $75 \mathrm{~mL}$, extraction cycle: 3 times

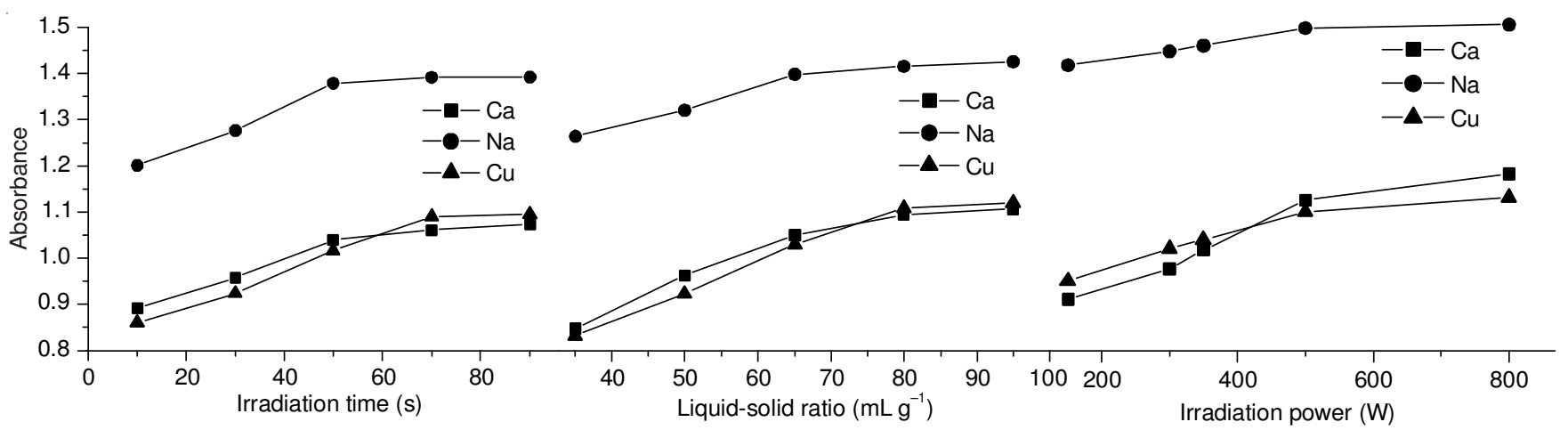

Fig. 2. Effect of irradiation time, liquid-solid ratio and irradiation power on the microwave-assisted extraction process of $\mathrm{Ca}$, Na and $\mathrm{Cu}$ extraction from Suaeda glauca Bge leaf 
of metal in leaf showed higher than those of seed except $\mathrm{Na}$ and $\mathrm{Ca}$ that may be close related to the salt of soil and water in this area since this area is rich in salt. In addition, early metabolism of leaf had apparently stronger than the seed metabolism, which resulted in the higher absorption capacity for toxic metal environment of the leaves than that of seed.

The results show that all herbs and vegetable plants contain most of the metals in the $\mu \mathrm{g} \mathrm{g}^{-1}$ range and that metal contents varied widely. The results in Table- 1 showed that the distribution of metals in leaf and seed showed a similar trend were in the following order: $\mathrm{Na}>\mathrm{Cu}>\mathrm{Ca}>\mathrm{Mg}>\mathrm{Cd}>\mathrm{Pb}>\mathrm{Cr}$. Seven metals are divided into the toxic trace metals $(\mathrm{Cu}, \mathrm{Pb}$, $\mathrm{Cd}$ and $\mathrm{Cr}$ ) and macronutrients ( $\mathrm{Na}, \mathrm{Mg}$ and $\mathrm{Ca}$ ). Food and agriculture organisation (FAO) and the World Health Organization (WHO) suggested that these elements $\mathrm{Ca}, \mathrm{Fe}, \mathrm{Cu}, \mathrm{Zn}$ are essential for all life forms when present in the daily dose. However, this study revealed that all the metals from Suaeda glauca Bge studied were accumulated to greater or lesser extents. Copper released from the plant has $2154 \pm 23 \mu \mathrm{g} \mathrm{g}^{-1}$ higher content than $\mathrm{Pb}, \mathrm{Cd}$ and $\mathrm{Cr}$. In this case, the normal range of $\mathrm{Cu}$ in edible vegetables range has reported ${ }^{16}$ between 3 and $30 \mu \mathrm{g} \mathrm{g}^{-1}$ (Table-2), which greatly exceeded phytotoxic range from 20 to $100 \mu \mathrm{g} \mathrm{g}^{-1}$. So Suaeda glauca Bge was found to be a good hypertolerant plant for $\mathrm{Cu}$ since it have the ability to accumulate high concentrations of metals in their tissues ${ }^{17,18}$.

\begin{tabular}{|c|c|c|c|c|}
\hline \multicolumn{5}{|c|}{$\begin{array}{c}\text { TABLE-2 } \\
\text { METAL CONCENTRATIONS FOR HEAVY METALS IN PLANTS }\end{array}$} \\
\hline $\begin{array}{l}\text { Metal concentrations } \\
\qquad\left(\mu \mathrm{g} \mathrm{g}^{-1}\right)\end{array}$ & $\mathrm{Cd}$ & $\mathrm{Cu}$ & $\mathrm{Pb}$ & $\mathrm{Cr}$ \\
\hline \multirow[t]{3}{*}{ Normal } & $0.1-1^{\mathrm{b}}$ & & $0.1-20^{\mathrm{b}}$ & \multirow{3}{*}{$0.2-1^{\mathrm{a}}$} \\
\hline & $0.03-0.5^{\mathrm{a}}$ & $3-30^{c}$ & $0.1-5^{\mathrm{a}}$ & \\
\hline & $0.05-2^{c}$ & & $0.5-10^{c}$ & \\
\hline Phytotoxic & $5-700^{c}$ & $20-100^{c}$ & $30-300^{c}$ & \\
\hline Hyperaccumulators & $\begin{array}{l}100=0.01 \\
(\%)^{\mathrm{a}}\end{array}$ & $\begin{array}{l}1000=0.1 \\
(\%)^{\mathrm{a}}\end{array}$ & $\begin{array}{c}1000= \\
0.1(\%)^{\mathrm{a}}\end{array}$ & $\begin{array}{c}1000=0.1 \\
(\%)^{\mathrm{a}}\end{array}$ \\
\hline
\end{tabular}

Table-1 showed that the content of $\mathrm{Cd}$ in the leaf and seed of Suaeda glauca Bge was between 84.49 and $61.52 \mu \mathrm{g} \mathrm{g}^{-1}$. Thus, it can be concluded that $\mathrm{Cd}$ content in the tissue of Suaeda glauca Bge was out of the normal range and at a toxic level, but not yet reached the level of Hyperaccu-mulators. The content of $\mathrm{Pb}$ in the leaf and seed of Suaeda glauca Bge was within normal range and close to phytotoxic range. However, the content of $\mathrm{Cr}$ has exceeded the normal range, posing an important environmental risk, though $\mathrm{Cr}$ have important roles in the metabolism of cholesterol as well as heart disease ${ }^{21}$. According to the WHO, the permissible limit for plants, based on the maximum allowed levels (MAL) in plants for $\mathrm{Cd}$ and $\mathrm{Cr}$ are listed in Table-2. But $\mathrm{Cd}$ and $\mathrm{Cr}$ are prohibited in any amount in edible plants. The long-term use of Suaeda glauca containing these elements as vegetable or herb may pose threat to human health and the environment. Deficiency or excess of macronutrients elements $(\mathrm{Ca}, \mathrm{Mg}$ and $\mathrm{Na})$, including the suitable abundance toxic metal $(\mathrm{Cu}, \mathrm{Cr})$, may cause a number of disorders, in addition, these elements also take part in neurochemical transmission and in variety of different metabolic processes ${ }^{22,23}$.

\section{Conclusion}

In view of the above facts, Suaeda glauca Bge growing on Dafeng seashore (eastern of Jiangsu, China) is not edible. However, as a source of biologically important elements, Suaeda glauca Bge may play an important pole in the accumulation of toxic metals, especially $\mathrm{Cu}$. Hence it is expected that plants with high concentrations of the above-mentioned elements could be the selection of phytoremediation of heavy metal in the studied area. We suggest that Suaeda glauca Bge, as a tolerant plant, can be used as tools for revegetation for erosion control in metals-contaminated area.

\section{ACKNOWLEDGEMENTS}

The authors are gratefully to the Natural Science Foundation of Education Department of Jiangsu Province (No. 13KJD150005), Jiangsu Provincial Key Laboratory of Coastal Wetland Bioresources and Environmental Protection (JLCBE12008).

\section{REFERENCES}

1. A. Boularbah, C. Schwartz, G. Bitton, W. Aboudrar, A. Ouhammou and J.L. Morel, Chemosphere, 63, 811 (2006).

2. A. Zayed, S. Gowthaman and N. Terry, J. Environ. Qual., 27, 715 (1998).

3. Z.H. Ye, S.N. Whiting, Z.Q. Lin, C.M. Lytle, J.H. Qian and N. Terry, J. Environ. Qual., 30, 1464 (2001).

4. Z.H. Ye, A.J.M. Baker, M.H. Wong and A.J. Willis, Ann. Bot., 80, 363 (1997).

5. Y.L. Zhang and B. Zhang, Chinese Food Nutr., 8, 46 (1997).

6. M.Q. Li, A.H. Zhu and W.F. Zheng, J. Xuzhou Normal Univ., 18, 57 (2000).

7. D.S. Zhou, Q.Z. Wang, M. Wang, Y.F. Dong, X. Feng and J.Y. Liang, Chinese Wild Plant Res., 30, 5 (2011).

8. F.T. Gu, J. Binzhou Educ. College, 5, 43 (1999).

9. M.B. Arain, T.G. Kazi, M.K. Jamali, J.A. Baig, H.I. Afridi, N. Jalbani and R.A. Sarfraz, Pedosphere, 19, 476 (2009).

10. Z.F. Wei, Y.G. Zu, Y.J. Fu, W. Wang, M. Luo, C.J. Zhao and Y.Z. Pan, Sep. Purif. Technol., 102, 75 (2013).

11. T.G. Kazi, M.K. Jamali, A. Siddiqui, G.H. Kazi, M.B. Arain and H.I. Afridi, Chemosphere, 63, 411 (2006).

12. R.C.F. Neves, P.M. Moraes, M.A.D. Saleh, V.R. Loureiro, F.A. Silva, M.M. Barros, C.C.F. Padilha, S.M.A. Jorge and P.M. Padilha, Food Chem., 113, 679 (2009).

13. A. Elik, Talanta, 71, 790 (2007).

14. B. Pérez-Cid, I. Lavilla and C. Bendicho, Anal. Chim. Acta, 378, 201 (1999).

15. B. Pérez Cid, A. Fernández Alborés, E. Fernández Gómez and E. Falqué López, Anal. Chim. Acta, 431, 209 (2001).

16. J.C. Igwe and A.A. Abia, Afr. J. Biotechnol., 5, 1167 (2006).

17. U. Krämer, Annu. Rev. Plant Biol., 61, 517 (2010).

18. A.J.M. Baker and R.R. Brooks, Biorecovery, 1, 81 (1989).

19. G. Visioli and N. Marmiroli, J. Proteomics, 79, 133 (2013).

20. R.E. Pugh, D.G. Dick and A.L. Fredeen, Ecotoxicol. Environ. Saf., 52, 273 (2002).

21. H.M. Perry, Hypertension and True Geochemical Environments in Relation to Health and Diseases, Academic Press, New York (1972).

22. A.M.O. Ajasa, M.O. Bello, A.O. Ibrahim, I.A. Ogunwande and N.O. Olawore, Food Chem., 85, 67 (2004).

23. S. Ahmed, A. Rehman, M. Qadiruddin and Y. Badar, J. Faculty Pharmacy, 2, 83 (1994). 